Inequalities of Redress:

Australia's National Redress Scheme for Institutional Abuse of Children

by Kathleen Daly

Professor Kathleen Daly

School of Criminology and Criminal Justice

Mt Gravatt Campus

Griffith University QLD 4111

AUSTRALIA

of $\quad+61(0) 73735-5625$

email: k.daly@griffith.edu.au

www.griffith.edu.au/professional-page/professor-kathleen-daly

Journal of Australian Studies (42): 2, pp. 204-16.

Please do not quote or cite without permission of the author.

24 March 2018 


\title{
Inequalities of Redress: \\ Australia's National Redress Scheme for Institutional Abuse of Children
}

Professor Kathleen Daly

School of Criminology and Criminal Justice

Griffith University

Brisbane QLD 4111

Australia

k.daly@griffith.edu.au

\begin{abstract}
The national redress scheme proposed by the Royal Commission into Institutional Responses to Child Sexual Abuse is unique and unusual in the world of government redress. It is unique with its inclusion of both care leavers and non-care leavers (it is the only government scheme to do so), and it is unusual in focusing on sexual abuse alone (18\% of government schemes do). These unique and unusual qualities come at a price for justice. Care leavers and non-care leavers are different groups with respect to their experiences of abuse and social status as child victims. Unless these group differences are explicitly recognised in guidelines for the monetary payment, care leavers will be disadvantaged. Two corrective measures are proposed: adopting an inclusive understanding of sexual abuse in closed and open settings, and addressing the negative bias that may result from care leavers' lower social status as children compared to that of non-care leavers. Their lower status is likely to affect (that is, devalue) judgements of the severity and impact of abuse.
\end{abstract}

Keywords: redress scheme; institutional abuse of children; care leavers; non-care leavers; monetary payment

\section{Acknowledgements}

My thanks and appreciation to editors Katie Wright, Shurlee Swain, and Kathleen McPhillips, other colleagues (Frank Golding, Robyn Holder, and Patrick Parkinson), the two 
anonymous reviewers, and Senior Research Assistant Victoria Meyer. This work was supported by the Australian Research Council under Grant DP170101470 (2017-2020).

\section{Author Bio}

Kathleen Daly is a professor in the School of Criminology and Criminal Justice at Griffith University, Brisbane. Her recent work compares redress schemes for institutional abuse of children worldwide, state-based monetary schemes for violent crime victims in Australia and other countries, and conventional and innovative justice responses to sexual and violent victimisation in different social and country contexts of violence. Her book, Redressing Institutional Abuse of Children (Palgrave Macmillan, 2014), was awarded the Christine M. Alder Book Prize from the Australian and New Zealand Society of Criminology (ANZSOC). She is Fellow of the Academy of the Social Sciences in Australia and of the American Society of Criminology, and Distinguished Criminologist and Fellow of ANZSOC.

\section{Disclosure Statement}

There is no financial interest or benefit arising from the direction application of this research.

Inequalities of Redress: Australia's National Redress Scheme for Institutional Abuse Kathleen Daly

\section{Introduction}

The first government redress scheme for institutional abuse of children began in 1993 in Canada. ${ }^{1}$ Since then, at least thirty-six government redress schemes have been concluded,

\footnotetext{
${ }^{1}$ The redress scheme was for St John's and St Joseph's Schools in Ontario. See Kathleen Daly, Redressing Institutional Abuse of Children (Basingstoke: Palgrave Macmillan, 2014), $28-31$.
} 
underway, or proposed in fourteen jurisdictions. ${ }^{2}$ The government schemes vary, but with the exception of two - the Australian Defence Force Reparations Scheme ${ }^{3}$ and the proposed Australian national scheme - they are the same in one way: they were established only for children who were placed in institutional or out-of-home "care", that is, for those who lived in "closed" settings such as residential facilities, orphanages, homes, foster care, ${ }^{4}$ training schools or detention centres. Today, this group is termed "care leavers", 5 and they are almost exclusively the subjects of government redress for institutional abuse of children worldwide. Of the thirty-four schemes for care leavers only, $82 \%$ address physical, sexual, and emotional abuse; $18 \%$ address sexual abuse only.

There is a second group, whom I call "non-care leavers", who were abused in "open" settings such as day schools, church parishes, clubs, and sports associations, typically by clergy, members of religious orders, or lay staff in religious organisations. Compared to care leavers,

\footnotetext{
${ }^{2}$ These figures draw from my international redress project as of January 2017. The figure of thirty-six is a minimum because it excludes a few council schemes in Scotland and many municipal schemes in Norway. The fourteen jurisdictions are Australia, Austria, Canada, Germany, Iceland, Ireland, Netherlands, New Zealand, Northern Ireland, Norway, Scotland, States of Jersey, Sweden, and Switzerland.

${ }^{3}$ This scheme was for youth cadets in a closed military institution, but they were not in institutional or out-of-home care.

${ }^{4}$ Foster care is out-of-home care, but not in a brick-and-mortar closed institution.

${ }^{5}$ By defining care leavers to include those in out-of-home care and detention, I adopt the approach taken by the Australian Senate, Community Affairs References Committee,
} Forgotten Australians: A Report on Australians Who Experienced Institutional and Out-ofHome Care as Children (Canberra: Commonwealth of Australia, 2004), 8. 
non-care leavers typically had one or more parents caring for them. Fewer redress schemes have been created for non-care leavers, and my international redress project has sourced thirteen nongovernment schemes (all but one is faith-based) in six jurisdictions. ${ }^{6}$ Of these, nine address abuse occurring in closed and open settings; most (62\%) focus solely on sexual abuse. ${ }^{7}$

Proposed by the Royal Commission into Institutional Reponses to Child Sexual Abuse (hereafter, Royal Commission) in September 2015, ${ }^{8}$ the Australian redress scheme is unique and unusual in the world of government redress. It is unique with its inclusion of both care leavers and non-care leavers (the only government scheme to do so), and it is unusual in focusing on sexual abuse alone (18\% of government schemes do). These unique and unusual qualities come at a price for justice. Care leavers and non-care leavers are different groups in ways that matter for justice. Unless these differences are explicitly recognised in the protocols guiding decisions for the monetary payment, care leavers are likely to be disadvantaged. The proposed scheme is unlike any other in the world today in terms of complexity. It has diverse claimant groups and offending organisations, federal-state governance, and shared costs by government and non-government organisations; and it will take into account relevant payments that claimants have received previously. This article focuses on diverse claimant groups and one component of the redress scheme, the monetary payment. ${ }^{9}$

\footnotetext{
${ }^{6}$ It is more difficult to source information on church (or other non-government) schemes or protocols; thus, thirteen is a minimum.

${ }^{7}$ Of the remaining four, one was for those in care, and three, for those not in care.

${ }^{8}$ Royal Commission into Institutional Responses to Child Sexual Abuse, Redress and Civil Litigation Report (Sydney: Royal Commission into Institutional Responses to Child Sexual Abuse, 14 September 2015).

${ }^{9}$ The proposed scheme has a monetary payment, counselling, and a direct personal response.
} 
As Golding suggests, a hierarchy of child abuse was established in 2013 with the Commonwealth's terms of reference for the Royal Commission, which centred on child sexual abuse. ${ }^{10}$ Care leavers have been critical of this, saying "[we] were violated in every sense in an institution, and being sexually used was just one of those violations". ${ }^{11}$ Depending on the source, estimates of sexual abuse in out-of-home care range from $21 \%$ to $55 \% .{ }^{12}$ However, we cannot turn back the clock and wish the Commonwealth had included other types of abuse in its terms of reference for the Royal Commission. ${ }^{13}$ With that reality in mind, this article develops two points.

${ }^{10}$ Frank Golding, "Sexual Abuse as the Core Transgression of Childhood Innocence: Unintended Consequences for Care Leavers," Journal of Australian Studies 42, no. 2 (this issue).

${ }^{11}$ Joanna Penglase, Orphans of the Living: Growing up in 'Care' in Twentieth-Century Australia (Fremantle: Curtin University Books, 2005), 145.

12 The figures are 21\% (Australian Senate, Forgotten Australians, 410); 25\% (Australian Senate, Forgotten Australians, 14, citing Jan O’Grady, Tasmanian Ombudsman, Interim Report on Abuse of Children in State Care as Children [Hobart, Tasmania,7 January 2004]); 45\% (Care Leavers Australia Network [CLAN] "A Terrible Way to Grow Up: The Experience of Institutional Care and Its Outcomes for Care Leavers in Australia,” 2008, 7); and 55\% (Elizabeth Fernandez et al., “"There's More to be Done; "Sorry” is Just a Word': Legacies of Out-of-Home Care in the 20th Century," Children Australia 42, no. 3 (2017): 176-97, 183.

${ }^{13}$ Care leavers had hoped this would be possible because the terms of reference included "other matters", but the Royal Commission decided that physical (or other) abuse could be considered only when it occurred in a context of sexual abuse. 
First, the scheme must give explicit attention to group differences between care leavers and non-care leavers. For the monetary payment, the proposed matrix has $40 \%$ for severity of abuse, $40 \%$ for severity of impact of abuse, and $20 \%$ for additional elements. The $20 \%$ recognises those who, at the time of abuse, had been state wards, experienced other forms of abuse alongside sexual abuse, were in a closed institution or without the support of family or friends, and had vulnerabilities related to a disability. ${ }^{14}$ This factor asks decision-makers to consider added values for the severity and impact of abuse, depending on its context and children's vulnerabilities. However, it can go further by recognising group differences in the context-dependent nature of sexual abuse and the social status of child victims. ${ }^{15}$

Second, unless corrective measures are taken, the individualised assessment for the monetary payment is likely to put care leavers at a disadvantage. This is because different groups will be subject to "equal treatment", and I anticipate that non-care leavers' experiences of abuse and their social status (as children) will be used as the standard against which the care leaver group may appear not to measure up. Evidence for my claim comes from a report by Finity Consulting that was prepared for the Royal Commission in 2015. In a short section, it compared average payments awarded by the Catholic Church in its Towards Healing protocol to those abused in different contexts. The average payment was $\$ 30,000$ for abuse in residential care (care leavers), but it was $\$ 50,000$ to $\$ 55,000$ for abuse in education and religious settings (largely noncare leavers). The report says the different amounts were "inconsistent with private session

\footnotetext{
${ }^{14}$ Royal Commission into Institutional Responses to Child Sexual Abuse, Redress Report, recommendations $15-17$.

${ }^{15}$ For those with a disability, abuse could have occurred in closed or open settings; furthermore, some closed institutions were established only for children and adults with disabilities.
} 
information", which suggested "a higher severity of abuse in residential settings" compared to other settings. ${ }^{16}$

This article has three parts. In the first, I define key terms and explain redress schemes. In the second, I discuss the care leaver / non-care leaver distinction, first with reference to evidence from the Royal Commission's Final Report, and then to the research literature. In the third, I discuss the problem of justice for different groups, its implications, and ways forward.

\section{Key Terms}

\section{Redress}

Redress means to rectify or correct and is a type of corrective or civil justice in response to private wrongs. It can be compared to criminal justice, which responds to public wrongs by criminal prosecution, trial, and punishment. ${ }^{17}$ Redress refers to all the activities, processes, and outcomes that provide a compensatory mechanism for harms or wrongs against an individual or group. Two redress mechanisms are civil litigation and redress schemes.

\section{Redress schemes}

\footnotetext{
${ }^{16}$ Finity Consulting Pty Limited, "National Redress Scheme Participant and Cost Estimates," (Sydney, July 2015), 40-41. Towards Healing is not a structured scheme, has no cap, and claims are negotiated. Other non-government schemes for which the Royal Commission has information (e.g. Salvation Army [Eastern District]) could be analysed to compare the two groups.

${ }^{17}$ This separation relates to two modes of law that address wrongs, which are called "private" and "public"; however, redress and civil litigation can and do occur alongside criminal prosecution.
} 
Redress schemes can operate alone or alongside civil litigation. They are formed in two ways: negotiated between lawyers for the plaintiffs and defendants, or stipulated by the offending party (i.e. government, church, or charitable organisation) with little or no negotiation. Unlike civil litigation, redress schemes do not resolve a legal dispute: they do not make findings of guilt or responsibility. As an administrative process, determinations of claims in redress schemes often use a lower evidence standard compared to court determinations, and different approaches are used to calculate a monetary payment. A redress scheme is the only feasible civil justice option for victims and survivors when credible evidence no longer exists, too much time has passed, and defendants are deceased or cannot be sued; it offers a potentially faster and less onerous justice process. A trade-off is that average monetary payments in redress schemes are lower (although not always) than "damages" (or compensation) awarded in a successful civil suit. At the same time, redress schemes can contain elements that do not feature in litigation outcomes: apologies, counselling, medical and dental benefits, educational scholarships, and memorials.

\section{Monetary payments}

The monetary payment in redress schemes can be based on a recognition of the abuse suffered, recognition of a policy wrong (such as forced removal of children), or claimant social welfare. Most redress schemes use an individualised assessment of abuse, which draws from ideas in personal injuries law. Each person is assessed against a grid or matrix that produces a score for the type and severity of abuse (or both abuse and impact), which ranges from low to high. The monetary payment is then pegged to a score. All individualised schemes constrain payments with maximum caps, and most government schemes have lower caps (maximum of $\$ 60,000$ to $\$ 80,000$ ), but a few are far higher. Two such schemes are the Irish Residential Institutions Redress Board (RIRB) and Canadian Indian Residential Schools 
Settlement Agreement (IRS, Individualised Assessment Payment), with caps of $\$ 423,000$ and $\$ 430,000$, respectively. ${ }^{18}$ These were highly unusual schemes in other ways: they held oral hearings, and claimants required legal representation; the "injuries" elements and burden of proof aligned closely with personal injuries at common law, including the need to produce medical or psychiatric reports.

Other monetary payments are not based on acts of abuse or specific injuries but rather on the recognition of the wrong or common experience of survivors. These pay a flat amount or one that is based on a formula applied to all claimants, such has the number of years spent in an institution. Some schemes combine the two. For example, the IRS scheme had a common experience payment and individualised assessment.

The Royal Commission's proposed scheme is partly modeled on the RIRB, although its cap is lower (proposed to be $\$ 200,000$, reduced by the Australian government to $\$ 150,000)$. No justification was given by the Royal Commission for its choice of redress scheme, except that some submissions "said [the RIRB] was a good redress model to consider" ${ }^{19}$ In the abstract perhaps, but the RIRB has been criticised as "protracted,

\footnotetext{
${ }^{18}$ Reported amounts vary by a chosen exchange rate. For the RIRB cap, I use the amount reported in the Royal Commission's Redress Report, 228 (calculated on 17 December 2014). For the IRS, the cap is $\mathrm{C} \$ 275,000$ for abuse and impact, with an additional amount for proven loss of wages, up to $\mathrm{C} \$ 250,000$; but together, the two cannot exceed $\mathrm{C} \$ 430,000$. I assume parity between the $\mathrm{C} \$$ and $\mathrm{A} \$$. Both schemes have generous provision for loss of opportunity or wages, which is atypical in redress schemes for institutional abuse of children.

${ }^{19}$ Royal Commission into Institutional Responses to Child Sexual Abuse, Redress Report, 228.
} 
expensive, difficult, and legalistic". ${ }^{20}$ There was no discussion in the Redress and Civil Litigation Report (hereafter Redress Report) of using a flat or common experience payment or of combining this with an individualised assessment, as occurs in some redress schemes. The proposed scheme is unusual in reserving $20 \%$ for particular survivor subgroups or contexts of abuse.

As one of fifteen members of the Commonwealth's Independent Advisory Council on Redress, I participated in discussions on the design and implementation of the redress scheme during 2017. The Commonwealth Redress Scheme for Institutional Child Sexual Abuse Bill 2017, tabled in Parliament on 26 October 2017, closely tracks what the Royal Commission proposed, with some amendments. ${ }^{21}$ As this article goes to press (March 2018), the bill is before Parliament for hearings and debate.

\section{Care Leavers and Non-Care Leavers}

The care leaver / non-care leaver distinction was elucidated by a Scottish politician in 2016 during a government inquiry into institutional abuse of children. Deputy First Minister John Swinney distinguished children who were abused "“in-care' and 'non in-care' settings". ${ }^{22} \mathrm{He}$

\footnotetext{
${ }^{20}$ Stephen Winter, “Two Models of Monetary Redress: A Structural Analysis," Victims \& Offenders (2017): 1-19, 7. DOI: 10.1080/15564886.2017.1280108.

${ }^{21}$ Among the Commonwealth's amendments is reducing the maximum payment from $\$ 200,000$ to $\$ 150,000$, limiting counselling to $\$ 5,000$ (rather than lifetime counselling), and excluding all youth and adults who have been convicted of any sexual offence, as well as those sentenced to imprisonment for five years or more for any crime. The latter two amendments are in the rules for the Redress Scheme Bill, which have not yet been tabled as this article goes to press.

${ }^{22}$ Deputy First Minister of Scotland John Swinney, "Update on Issues Relating to the
} 
did so because some advocates wanted to see the inquiry widen to include abuse "in ... local parishes, day schools and youth organisations" (that is, to include non-care leavers). Wishing "to put the matter beyond any doubt", Swinney said the inquiry would focus only on children and young people in care.

Swinney defined "in-care" settings as those in which "institutions and bodies have legal responsibility for the long-term care of children in the place of a parent, with all of the legal and moral obligations that status carries. [This] is different to ... 'non in-care' settings, such as day schools and youth groups", in which other adults had "a duty of care on a shortterm basis, but crucially not replacing the role of parents". In making this distinction, Swinney drew attention to differences in the legal and moral contexts of abuse when children are without a caring parent or protective adult. He shows the importance of marking such group differences in an inquiry or redress scheme.

\section{Defining and comparing the groups}

I adopt the Australian Senate's definition of care leavers to include children in out-of-home care and detention, but distinguish the two when relevant. Care leavers were state wards or placed by family members in out-of-home care, or they were committed to youth detention. This occurred for many reasons. For those in out-of-home care, a key one was a "lack of financial support for families in crisis ... or for unmarried mothers"; children were also removed because of "sex abuse by a parent or step-parent". ${ }^{23}$ Children grew up in "total

Scottish Child Abuse Inquiry,” press release 17 November 2016, https://news.gov.scot/speeches-and-briefings/update-on-issues-relating-to-the-scottish-childabuse-inquiry, quoted extracts are, respectively, on 4, 3, 4, 4-5.

${ }^{23}$ Australian Senate, Forgotten Australians, 73, 65. 
institutions", that is, batch living of a large group of "inmates", controlled by a small supervisory staff. The major spheres of life (sleeping, playing, working) were all in "the same place and under the same single authority". ${ }^{24}$ Survivors recall a "dehumanizing institutional environment", one of being "totally at the mercy" of staff with no one to turn to. They lived in "a constant fear of sexual abuse [and were subject to] deprivations of food and schooling, forced labour, and medical neglect", ${ }^{25}$ alongside physical and sexual abuse.

Palmer and Feldman argue that out-of-home care and detention are more likely to "embrace organisational cultures that make them ... susceptible to ... child sexual abuse ..." compared to other closed settings such as boarding schools. ${ }^{26}$ Why do the authors say that boarding schools are different? They argue that children in out-of-home care and detention were of low social status, and supervisory staff more readily used techniques of neutralisation to deny the victim and the harm. Palmer and Feldman's distinction is important because it alerts us to the role of a child's social status, not only in perpetrators' justifications and excuses for abuse, but also as I shall argue, subsequent responses to it.

Non-care leavers typically had one or more parents caring for them. They were abused in a range of settings such as day schools, church parishes, clubs, and sports associations; and based on evidence from the Royal Commission (below), most often by clergy, members of

${ }^{24}$ Erving Goffman, Asylums (New York: Anchor Books, 1961), 4, 6, 7.

${ }^{25}$ Penglase, Orphans of the Living, 48; Frank Golding, submission to Royal Commission into Institutional Responses to Child Sexual Abuse, Redress and Civil Litigation Consultation Paper (Sydney: Commonwealth of Australia, 2015), 28 February 2015, 2.

${ }^{26}$ Donald Palmer and Valerie Feldman, "Toward a More Comprehensive Analysis of the Role of Organizational Culture in Child Sexual Abuse in Institutional Contexts," Child Abuse \& Neglect 74 (2017): 23-34, 29. 
religious orders, or lay staff in religious organisations. As we learn next, non-care leavers also faced adverse circumstances growing up, but these did not reach the same degree of family "crisis or hardship", as described by the Australian Senate for care leavers. ${ }^{27}$

More has been written on the social and economic circumstances of care leavers (as children and as adults) than non-care leavers. There is no one source that compares the two; thus, I piece together what is available. Care leavers came from families marked by "economic stress and social disadvantage ... poverty [and] violence". ${ }^{28}$ By comparison, Death's survey of sexual abuse survivors in Christian institutions, a sample composed predominantly of noncare leavers, shows that as children, $60 \%$ experienced one or more "adverse circumstances" at the time of abuse. These were associated with family violence and parental abuse of alcohol or drugs. Economic stress or poverty was not on the list. ${ }^{29}$ For education, surveys of care leavers by CLAN and Fernandez et al. show that $12 \%$ and $16 \%$, respectively, had gone on to complete a university degree. Death's survey finds that $52 \%$ had a university degree. ${ }^{30}$ From this, we can reasonably conclude that non-care leavers more likely grew up in working or middle-class families compared to care leavers. Indeed, as children, care leavers were viewed by society and institutional staff as a morally and socially inferior class of children, as

\footnotetext{
${ }^{27}$ Australian Senate, Forgotten Australians, 65.

${ }^{28}$ Australian Senate, Forgotten Australians, 79, 82.

${ }^{29}$ Jodi Death, ““They Did Not Believe Me’: Adult Survivors' Perspectives on Child Sexual Abuse by Personnel in Christian Institutions" (Brisbane: Crime and Justice Research Centre,
} May 2013).

${ }^{30}$ CLAN, “A Terrible Way to Grow Up," 9; Fernandez et al., "There's More to Be Done," 185; Death, "They Did Not Believe Me," 12. 
"undeserving "moral dirt"”.31

\section{Evidence from the Royal Commission}

The Royal Commission's Final Report analyses 6,875 survivors who came forward in private sessions to May 2017. Although it is a self-selected group who decided to speak to a commissioner in an inquiry on child sexual abuse, it is a single source that has potential to compare care leavers and non-care leavers. Of the 6,875 survivors in private sessions, the largest share was abused in out-of-home care pre-1990 $(\mathrm{N}=2,478$, or $36 \%)$, with another $8 \%$ in youth detention. ${ }^{32}$ For the remainder, the top three abuse contexts were schools (32\%), religious activities (15\%), and recreation, sports, and clubs (6\%), with $11 \%$ in other contexts.

My comparison of the two groups is sharp-edged, and classification is not always straightforward. ${ }^{33}$ Well-known variation exists within each group. In Australia, many care

${ }^{31}$ Harry Ferguson, "Abused and Looked After Children as 'Moral Dirt': Child Abuse and Institutional Care in Perspective," Journal of Social Policy 36, no. 1: 123-39, 136. Ferguson analysed children in industrial schools and homes in Ireland.

${ }^{32}$ Royal Commission into Institutional Responses to Child Sexual Abuse, Final Report, (Sydney: Royal Commission into Institutional Responses to Child Sexual Abuse, 15 December 2017), Preface and Executive Summary, 11. Percentages are rounded. The total in out-of-home care is $42 \%$, when including an additional 4\% in care from 1990 onwards and $2 \%$ for whom the time frame was not known. With multiple contexts given, the total adds to $112 \%$. Adjusting the figures to add to $100 \%$, all those in out-of-home care and detention add to $44 \%$.

${ }^{33}$ Some abuse contexts are closed settings (such as the armed forces), but children are not in care. Boarding schools are difficult to categorise because some child wards were placed in 
leavers are members of the stolen generations or former child migrants and prefer to be so known. ${ }^{34}$ For non-care leavers, abuse occurred in a diverse set of religious and secular settings. There are also points of overlap. In private sessions, $59 \%$ of 6,875 survivors "said they were sexually abused in an institution managed by a religious organisation". ${ }^{35} \mathrm{My}$ recalculation of the figures finds that the share was higher for non-care leavers $(65 \%)$ than those in out-of-home care (pre-1990) $(50 \%),{ }^{36}$ but in general, there are shared experiences of abuse in environments staffed by religious personnel or having a religious imprimatur.

The Royal Commission's Final Report analyses survivors in historical out-of-home care (pre-1990) and calls attention to a "diversity of survivors", identifying five subgroups: children and young people (4\%), Aboriginal and Torres Strait Islanders (14\%), culturally and linguistically diverse (3\%), having a disability at the time of abuse (4\%), and in prison at the time of the private session $(10 \%) .{ }^{37}$ However, no comparisons are made of care leavers and

them, as occurred in Western Australia's Country High School Hostels.

${ }^{34}$ Conventions for capitalisation of care leavers and other groups vary; in this article, I use lower case to refer to all subgroups of care leavers. The survey by Fernandez et al., "There's More to Be Done," shows identities to be forgotten Australians (75\%), child migrants (10\%), stolen generations (6\%), with $8 \%$ giving no identity, 179 .

${ }^{35}$ Royal Commission into Institutional Responses to Child Sexual Abuse, Final Report, Preface and Executive Summary, 11; and of those abused in religious organisations, for $62 \%$, it was the Catholic Church (12). Because government authorities contracted with church and charitable organisations to run out-of-home care, there is shared responsibility for abuse.

${ }^{36}$ Royal Commission into Institutional Responses to Child Sexual Abuse, Final Report, Preface and Executive Summary, recalculated from figures on 11, 50-51.

${ }^{37}$ Royal Commission into Institutional Responses to Child Sexual Abuse, Final Report, vol. 
non-care leavers or among the five subgroups. The Final Report says that of all those in private sessions, $56 \%$ "experienced poor educational outcomes or economic insecurity", ${ }^{38}$ but the percentage is not broken down by subgroups.

\section{Analysis of the literature}

Researchers have not compared care leavers and non-care leavers. The distinction is not remarked upon, in part because the literature itself is segregated. One stream focuses on abuse and redress of those in institutional and residential care (care leavers) ${ }^{39}$ while another focuses on those in church or faith-based settings, particularly those abused by clergy or members of religious orders. ${ }^{40}$ For the latter, we do not know whether survivors

11; vol. 5, 14, 16, 19, 21, 23.

${ }^{38}$ Royal Commission into Institutional Responses to Child Sexual Abuse, Final Report, vol. 5,89 .

${ }^{39}$ Indicative examples are Daly, Redressing; Fernandez et al., "There's More to Be Done"; Kjersti Ericsson, "Victim Capital and the Language of Money: The Norwegian Process of Inquiries and Apologies," The Journal of the History of Childhood and Youth 8, no. 1 (Winter 2015): 123-37; Richard Hil and Elizabeth Branigan, eds., Surviving Care: Achieving Justice and Healing for the Forgotten Australia (Robina: Bond University Press, 2010); Penglase, Orphans of the Living; Johanna Sköld and Shurlee Swain, eds., Apologies and the Legacy of Abuse of Children in 'Care' (Basingstoke: Palgrave Macmillan, 2015); Winter, "Two Models of Monetary Redress". Independent or public inquiries are likewise segregated, with the exception of the Australian Royal Commission and the Independent Inquiry into Child Sexual Abuse in England and Wales.

${ }^{40}$ Indicative examples are Judith Courtin, "Sexual Assault and the Catholic Church: Are 
are care leavers or not — the distinction is not made — but the dominant impression is of abuse in day schools and parish settings, not closed institutions. I compare the thrust of each stream to highlight differences between care leavers and a large group of non-care leavers.

The care leaver stream analyses "abuse in out-of-home care within the broader context of human rights and ... children's rights violations"; ${ }^{41}$ the clergy abuse stream analyses "clerical child sexual abuse ... pedophile priests ... and the sexual exploitation of children”, with a focus largely on the Catholic Church. ${ }^{42}$ The care leaver stream is concerned not only with acts of physical and sexual abuse, but also with the broader environment of control, abuse, and neglect in closed settings. The clergy abuse stream is concerned with sexual abuse by individual priests, the shifting of offenders to other parishes (where they offended again), cover-ups by church and police authorities, and survivors' (and their families') sense of betrayal and mistreatment by church authorities.

Victims Finding Justice?” (PhD thesis, Faculty of Law, Monash University, 2015); Kate Gleeson and Timothy Willem Jones, "Feminist Contributions to Justice for Survivors of Clerical Child Sexual Abuse,” Australian Feminist Law Journal 41, no. 2 (2015): 201-5; other contributors to the issue; Marie Keenan, Child Sexual Abuse and the Catholic Church (New York: Oxford University Press, 2012); Patrick Parkinson, "Child Sexual Abuse and the Churches: A Story of Moral Failure?," Current Issues in Criminal Justice 26, no. 1 (2014): 119-38. Some special issues or edited collections centre on child sexual abuse but do not distinguish analyses of care leavers, non-care leavers, or other groups.

${ }^{41}$ Johanna Sköld and Shurlee Swain, "Introduction," in Apologies and the Legacy of Abuse of Children in 'Care', 2.

${ }^{42}$ Gleeson and Jones, "Feminist Contributions," 201. 
Each stream identifies a different problem to be addressed. The former holds the state accountable for breaching its statutory duty of care, while recognising that religious and charitable organisations were often responsible for the day-to-day running of facilities. The latter holds the Catholic Church, in particular, the church hierarchy to account for sexual abuse: they should "tell the truth and be criminally accountable", particularly for "crimes of concealment of sex offences". ${ }^{43}$ Advocates emphasise the power and wealth of the Catholic Church and tax concessions for all religious institutions. By comparison, government coffers are more limited. ${ }^{44}$ Differences between religious and government institutions in wealth and assets create problems for fashioning appropriate monetary payments in one redress scheme.

The public face of accountability is less visible for care leavers, with a small number of people named; however, for clergy sexual abuse, there are many known faces, named priests, bishops, and high-level church authorities. The identification of cover-ups by police authorities is common to both, but the clergy sexual abuse stream can trace abuses of church power and coverups to national and international networks. The higher moral standing of offending clergy makes their abuse of children in open settings more visibly wrong ${ }^{45}$ than that of offending staff in closed settings.

\footnotetext{
${ }^{43}$ For the former, see Micah Projects and Historical Abuse Network, Framework for Justice (2015), http://micahprojects.org.au/assets/docs/Publications/2015-National-Framework-forJustice.pdf (accessed 21 November 2017). For the latter, see Courtin, "Sexual Assault and the Catholic Church,” 62 and sections 3.3 and 3.4, more generally.

${ }^{44}$ If governments are funders of last resort in a national scheme, the contribution is estimated to be $47 \%$, and the non-government contribution, 53\%. Finity Consulting, "National Redress Scheme," 8.

${ }^{45}$ I credit Victoria Meyer for this point.
} 
For these reasons, clergy sexual abuse has captured the attention of media and government. ${ }^{46}$ It has eclipsed a concern with systemic institutional abuse experienced by care leavers, which as Swain suggests, "has proven far harder to make". ${ }^{47}$ A recent example is an ABC documentary Undeniable, which aired the week the Royal Commission delivered its Final Report: it focused solely on those who brought clergy sexual abuse to national attention. ${ }^{48}$ Care leavers were once the subject of television series, books, and feature stories. However, these exposés are less evident today and appear less compelling to the Australian public and government than they once were. ${ }^{49}$

\section{The Problem of Justice for Different Groups}

\footnotetext{
${ }^{46}$ For review and references, see Golding, "Sexual Abuse as the Core Transgression," 9, 1113, and associated footnotes.

${ }^{47}$ Shurlee Swain, "Why Sexual Abuse? Why Now?," in Apologies and the Legacy of Abuse,
} 93.

${ }^{48}$ Paul Kennedy, "Undeniable: The Advocates and Agitators Who Fought for Justice," ABC News, 12 December 2017. An ABC News website lists nineteen "key events that led to the child abuse royal commission"; of these, all but two are of abuse by clergy or in faith-based settings. See http://www.abc.net.au/news/2017-12-12/royal-commission-child-sexual-abusetimeline/9222816 (accessed 27 January 2018).

${ }^{49}$ Commentators trace Julia Gillard's announcement of a Royal Commission in November 2012 to her concerns with Catholic clergy abuse and police cover-ups. See Frank Golding, "Mismanaging Expectations: The Dominance of Sexual Abuse at the Royal Commission," Paper given to Biennial European Social Science History Conference,” Valencia, 30 March 2 April 2016, on file with the author. 
In calling attention to group differences between care leavers and non-care leavers, my aim is not to suggest that one group suffered more, or that one group's experiences of abuse was "worse" than another's, or that one group should receive a higher average monetary payment. That is and would be wrong. Rather, I am calling attention to group differences that matter for justice, with respect to the monetary payment. Two key differences are the experiences of abuse and social status of child victims.

\section{Experiences of abuse in total institutions}

Care leavers were abused in total institutions, where sexual abuse is diffuse and part of a sexualised environment, in which there is no separation in the spheres of life. For these reasons, it can be difficult for survivors to trace sexual and other abuses ("injuries") to acts that occurred on specific dates, or to obtain documents that can verify what occurred.

The following experiences of care leavers would not be relevant to non-care leavers: high levels of physical abuse (80\%) alongside sexual abuse; "humiliating, degrading, and invasive" strip searches; sexual abuse during medical procedures and psychiatric treatment; and frequent abuse by "older and bigger" children. ${ }^{50}$ Care leaver Golding has memories of "a complete lack of privacy", which caused "children to feel embarrassed and humiliated"; witnessing sexual abuse and living "in a state of constant fear [of being] the next victim"; "seeing and hearing children being abused by staff and older boys", but being unable to "recall dates and names of perpetrators and victims"; older boys' abuse of those younger "accepted" as a "way of life"; and ongoing violence and the threat of violence creating "a climate of continual fear, humiliation, and intimidation, in which vulnerable and demoralised

\footnotetext{
${ }^{50}$ Royal Commission into Institutional Responses to Child Sexual Abuse, Final Report, vol.
} $11,65,70,71-73$. 
children ... could be coerced into sexual behaviour". ${ }^{51}$ The implications are that the guidelines for an individualised assessment of abuse must include the diffuse character and wider range of sexual abuses that occur in total institutions, which are not evident for children living in a family home.

\section{Social status of child victims}

Care leavers were not only viewed as a morally and socially inferior class of children, but also as "impure children" (i.e. not innocent) and "systematically regarded as second-class citizens, as undeserving of the kinds of love and care afforded to [children who were not in care] ${ }^{.52}$ If, as children, care leavers were viewed in these ways, their claims for monetary redress, as adults, may also be seen in the same light, even if unconsciously, by scheme decision-makers. In other words, care leavers' lower social status as children may devalue assessments of the perceived severity of abuse and its impact, compared to assessments made of non-care leavers.

My argument draws from the criminological literature on "ideal" and "non-ideal" victims, and those "deserving" and "undeserving", who are located in a "hierarchy of victimisation". ${ }^{53}$ In general, child victims are considered to be ideal or deserving because they are "weak, vulnerable, innocent, and deserving of help, care, and compassion", as

\footnotetext{
${ }^{51}$ Frank Golding, submission to Royal Commission into Institutional Responses, Issues Paper 6, "Redress Schemes" (Sydney: Commonwealth of Australia), 19 May 2014, 4-5.

${ }^{52}$ Ferguson, “Abused and Looked After Children," 134.

${ }^{53}$ Nils Christie, "The Ideal Victim," in From Crime Policy to Victim Policy, ed. Ezrah Fatttah (London: Macmillan, 1986), 17-30; Eamonn Carrabine et al., Criminology: A Sociological
} Introduction (London: Routledge, 2004), 115-17. 
compared to "low status, powerless groups ... such as the homeless, the unemployed, those with alcohol and drug problems, and sex workers". ${ }^{54}$ How do these ideas relate to differing child victim groups? There are some commonalities between those abused in care and not in care: children's reports to family members or authorities were not believed, although care leavers, as children, were less likely to have a protective adult to whom they could turn. But if, as Ferguson suggests, children in out-of-home care were viewed as "impure" and of low social status, their status as child victims (like those in detention) would be lower on a hierarchy of victimisation compared to children not in care. ${ }^{55}$ The implication is that scheme decision-makers must work against these and other biases in determining the severity of the abuse and its impact. Evidence of bias comes from one source (Finity Consulting's analysis of the Towards Healing protocol), and other analyses should be carried out.

Palmer and Feldman suggest that it was easier for adults to justify abusing children in out-of-home care and detention because they were "members of low status or pariah groups" ${ }^{56}$ Because of their status, it was easier for state and institutional authorities to justify inadequate education, food, clothing, medical, or dental care. One consequence is that many care leavers today are handicapped educationally, socioeconomically, and physically; many struggle with literacy and numeracy. This may put them at a disadvantage in applying to and participating in a redress scheme.

\footnotetext{
${ }^{54}$ Carrabine et al., Criminology, 116-17.

${ }^{55}$ Compare this with Ericsson, "Victim Capital," an analysis of different money payments for care leavers in Norway; these stem from differing "sufferings" and varied local regulations and budgetary constraints. Ericsson analyses within group differences, but my focus is on victimisation and social status between groups.

${ }^{56}$ Palmer and Feldman, "Role of Organisational Culture," 30.
} 


\section{Conclusion and Implications}

The Royal Commission faced an unenviable task in proposing a national redress scheme for a large number of claimants who shared no other experience except being sexually abused in an organisation outside a family setting. No other world scheme has sought to address such a diverse group of survivors and offending organisations. The terms of reference for the Royal Commission produced a profound instability: a requirement to devise one redress scheme for two different groups: care leavers and non-care leavers.

Compared to non-care leavers, care leavers as children:

(1) grew up in total institutions, in which sexual abuse was both public (that is, witnessed or heard) and private, both direct and more diffuse in a sexualised and violent environment, one in which sexual abuse occurred in all spheres of living, working, and sleeping;

(2) were considered to be and treated as low status, second-class children, and as morally and socially inferior to other children;

(3) experienced a greater degree of familial economic stress and social disadvantage before being removed from families or placed in care; and

(4) grew up in total institutions, inadequately schooled, clothed, fed, cared for, and loved; and, as a consequence, are today more likely to be educationally, socioeconomically, and physically handicapped, and to seek remedies for these disadvantages.

I argued that (1) and (2)—-sexual abuse experiences and social status as children-will have a direct disadvantaging impact on care leavers, as a group, in assessments of the monetary payment, unless corrective action is taken. The Royal Commission noted item (3), when discussing what it referred to as the "compounding" effects of abuse or deprivation, which 
occurred for a child in both a familial and institutional setting, in the $20 \%$ factor. ${ }^{57}$ Item (4) relates to other redress elements sought by care leavers. In addition to counselling, these are access to medical and dental services, housing, and specialist support services, and to adult literacy and numeracy programs.

The first recommendation in the Redress Report calls for a "process of redress" that provides "equal access and equal treatment of survivors". ${ }^{58}$ Applying the idea of equal treatment to different groups produces an equality problem: who is the presumptive survivor and applicant of the redress scheme? In asking this question, an analogy can be made to feminist research on gender equality, which asks: is the presumptive paid worker or citizen male? Can women only be equal to men if they accord with a "male standard"?

The Commonwealth's proposed assessment matrix has not been made public. Furthermore, we do not know what the specific decision-making guidelines will be. I am assuming that, like other individualised assessments, the matrix will frame sexual abuse (and associated physical abuse) within a personal injuries framework, which considers the types and frequency of specific acts of abuse, for which a claimant can recall details of perpetrators, places, and times; and then considers the subsequent mental and physical impact of what occurred. A current unknown is the degree to which guidelines for decisions will hew more closely to an administrative method than to strictly legal criteria and evidence. ${ }^{59}$ In

${ }^{57}$ Royal Commission into Institutional Responses to Child Sexual Abuse, Redress Report, 238.

${ }^{58}$ Royal Commission into Institutional Responses to Child Sexual Abuse, Redress Report, 4. Equal treatment for survivors was defined as "regardless of the location, operator, type, continued existence or assets of the institution in which they were abused".

${ }^{59}$ Redress schemes are, by definition, administrative, but some schemes place greater 
either event, a personal injuries framing is not well suited to care leavers for whom sexual abuse was both direct and diffuse, and interwoven in everyday life, which make it difficult to identify specific incidents and other required details.

The social status as child victim will operate in subtle ways in determinations of the severity of abuse and its impact. Because care leavers were viewed as inferior to other children, they are lower in the hierarchy of victimisation compared to non-care leavers. Their lower status as child victims is likely to devalue not only their abuse experiences, but also judgements of the impact of abuse. Further, given item (4) above, care leavers are less likely to have the resources to provide compelling evidence of impact, such as expert reports.

To put the case in stark sociological terms, the bodies and lives of higher status children may matter more to redress scheme decision-makers, their abuse may be seen as more serious, and the impact of abuse may be viewed as more dramatic and compelling. With a scheme that includes both care leavers and non-care leavers and that focuses solely on sexual abuse, care leavers' experiences of abuse and the impact of abuse may appear less worthy than that of noncare leavers. Although I have emphasised differences between care leavers and non-care leavers, I do not wish to diminish the importance of other subgroups. These are best understood, I believe, as subgroups within the larger set of care leavers and non-care leavers.

How, then, does my argument relate to the $20 \%$ factor, which recognises those abused in care and total institutions? Might it ameliorate the equal treatment problem? My answer is no. The reason is that abuse severity in an individualised assessment must embed and be inclusive of the experiences of both groups, not be based on one. If, for example, witnessing abuse or being in a sexualised environment or experiencing intrusive medical examinations

emphasis on legal criteria and specific types of evidence than others. 
(among others) are not on the list of types and severity of sexual abuse, the $20 \%$ factor (which includes associated physical abuse) will not be triggered.

\section{Implications}

I have suggested that corrective action is necessary to ensure that care leavers are not disadvantaged as claimants for the monetary payment. This comprises two aspects. The first is addressing the problem of group differences. Scheme planners and decision-makers must ask: does the matrix take into account group similarities and differences in the experiences of abuse? Is "sexual abuse" inclusive of the experiences of children in total institutions? How is the status of the child victim affecting decisions of abuse severity and impact? In what ways do a care leaver's experiences of abuse and its impact seem to be less worthy than a non-care leaver's? There must be continual review and reflection on the subtle influences and biases of a child victim's social status on determinations of abuse severity and impact.

The second is how to relate an inclusive model of abuse severity and impact to the $20 \%$ factor. This can be accomplished by carrying out what the Royal Commission proposed: amplify values for abuse and impact for specific groups. Alternatively, we could think of the $20 \%$ in a more radical way: as a payment determined by a common experience formula. This could take the form of a cash payment, or the amount could be converted to benefits or services of a claimant's choosing, such as medical, dental, or housing. For the amount, it could be $20 \%$ of the $\$ 150,000$ (or perhaps higher, if thought appropriate). The counselling amount, now capped at $\$ 5,000$, could also be converted. There are varied forms this could take, but survivors should have the option of seeking monetary redress (or benefits and services in lieu) without completing an application for an individualised assessment of abuse.

I put forward my argument assuming that the redress scheme will focus on sexual abuse of children, not as care leaver advocacy groups would wish, on additional forms of 
physical and emotional abuse and neglect. However, it is plain that these exclusions will be unfinished business for care leavers and a basis of future liability for offending organisations. The problem will not go away. 